\title{
562 Book reviews
}

fields; a fierce commitment to sharing and to "users" ... that defines both priorities and vision' (p. 3). This reader missed the sense of contention and comparison that is so successfully incorporated in the other text. And, as articles in the latest special issue of the journal Organised Sound (Alternative Histories of Electroacoustic Music (2017) 22(2)) show, computer music was developing on campuses across the world at the same time as Stanford was blooming. That slight caveat notwithstanding, this is a fascinating book that expresses extensive archive and oral-historical work, and a valuable component in the emerging picture of the relationship between music and technology in modernity.

TIM Boon

Science Museum

Robert J. Richards and Lorraine Daston (eds.), Kuhn's Structure of Scientific Revolutions at Fifty: Reflections on a Science Classic. Chicago: The University of Chicago Press, 2016. Pp. 208. ISBN 978-0-226-31720-5. £17.50 (paperback).

doi:10.1017/S0007087417000784

History, if viewed as a repository for more than anecdote or chronology, could produce a decisive transformation in the image of Thomas Kuhn's The Structure of Scientific Revolutions (1962) by which we are now possessed. Anyone who gets the reference in that sentence will want to seek out this superb volume. Its distinguished cast of contributors show how instructive Kuhn's book remains even though no one now accepts his account of scientific change-paradigm shifts and all that - as correct. The key to continuing to learn from Structure, we come to see, is to do to it what Kuhn urged us to do to science: historicize it, then put the results to generalizing work.

Since Steve Fuller's Thomas Kubn: A Philosophical History for Our Times (2000), the Cold War has been conspicuous among the historical contexts in which to place Structure and its success. For Fuller, Kuhn's picture of the self-directing nature of progressive scientific communities, insulated from interference and even criticism, derived from his patron James Conant's blueprint for post-war American science. George Reisch's opening chapter offers a partly dissenting and partly complementary response. Yes, when, in 1947, Kuhn first glimpsed the discontinuous character of conceptual change in science - the fundamental insight behind his later notion of paradigm shifts - he was preparing to teach on Conant's science-by-historical-example course at Harvard. But Conant himself endorsed a continuity-of-knowledge picture. For Reisch, what Kuhn and Conant nevertheless shared was a stress on the phenomenon of the 'captive mind', as embodied in the Communist true believer and the brainwashed American soldier. Loyalty to phlogiston chemistry after Lavoisier, in Conant's view, was down to captive minds. To the alarm of Cold Warriors such as the geneticist-historian Bentley Glass, Kuhn appeared to normalize the captive-mind state as functional for science.

Before Kuhn was a historian-philosopher who put scientific training qua paradigm indoctrination in the spotlight, he had trained as a physicist, specializing in the applied end of mid-1940s quantum mechanics, with a break between his undergraduate and postgraduate studies for war work on radar jamming. In a close reconstruction of Kuhn's trajectory before Structure, Peter Galison reveals how the particular, in some ways idiosyncratic, kinds of physics that Kuhn practised in the mid-1940s - highly individualized rather than team-based, and very loosely constrained by empirical data - predisposed him in his post-physics phase to find the theoryover-experience developmental psychology of Jean Piaget and others attractive in hammering out the details of a discontinuous, schema/crisis/new-schema account of scientific progress. As David Kaiser documents, the borrowings from contemporary psychology did not stop there. Kuhn in the 1950s also drew extensively on the "New Look," post-gestalt experimental psychology of Jerome Bruner and Leo Postman, and even on psychoanalysis. No wonder that psychologists bulked larger than any other disciplinary tribe as Kuhnian correspondents and enthusiasts throughout the 1960s. 
What, exactly, is a paradigm? The Kuhnian replies: an exemplary problem-solving achievement, plus the disciplinary matrix supporting its extension. But what makes some examples paradigmatic and others not? Kuhn struggled for decades to identify criteria that satisfied him or anyone else. In working out what Kuhn was striving for, Norton Wise counsels, we should take seriously Kuhn's belief that his 1978 book Black-Body Theory and the Quantum Discontinuity, 1894-1912 was the fullest historical expression of the general analysis of Structure. On that view, a paradigm for Kuhn was highly technical, even esoteric - which made seminars with him exercises in reinhabiting the problem worlds of very difficult past science. As for Kuhn's inability to give a clear explication of paradigms, that just makes Kuhn, for Ian Hacking, the inheritor of a muddle that goes all the way back to antiquity, when deductive logic first became the gold standard for reasoning, and the artful use of enlightening examples got filed under 'rhetoric'. Ever after, it has been nearly impossible to make sense of, much less vindicate, reasoning based not on truth-preserving syllogisms but on examples and their extensions. Turning that pessimistic message on its head, Lorraine Daston suggests that if anyone is in a position to contribute constructively to the understanding of example-based knowledge, it is, thanks to Kuhn, historians of science. In taking up that mission, furthermore, they would not only help with a timely research programme but also recapture something of the generalizing ambition that got lost when the historicizing of science became an end unto itself.

From the mid-1960s, Kuhn was being sent the essays of students asked to evaluate this or that scientific change as a Kuhnian revolution. The assignment may be an oldie but, in certain hands, it is nevertheless a goodie. As one would expect from Wise's chapter, Daniel Garber judges that the Scientific Revolution was not a Kuhnian revolution, because, argues Garber, there was no comprehensive regime that replaced the rejected Aristotelianism, but instead lots of distinctive bodies of theory and practice - Cartesian, Baconian, chymical, etc. - pursued in tandem. In a survey of biomedicine in the latter half of the twentieth century, Angela Creager looks at the role of model systems and their extensions as in some ways bearing out Kuhnian points about the functioning of exemplars, and in other ways not, notably in the materiality of such systems as itself a driver of change.

The volume closes with the sociologist Andrew Abbott's reflections on 'Structure as cited, Structure as read'. The citation data suggest that, on the whole, Structure has for a long time been cited generically, as a standard source for the idea-not at all original to Kuhn - that views about what counts as knowledge and how to acquire it change. Abbott also reports on his own rereading of the book, especially on the speculations it provoked about systems of knowledge that, as with the social sciences in our day, seem not so much to progress as to cycle endlessly through the same set of basic conceptual and methodological options. It is a fitting tribute to Kuhn's book that it can be seen even now to raise challenges that we barely know how to articulate, let alone answer.

GREGORY RADICK University of Leeds

Thomas J. Misa and Jefrerey R. Yost, FastLane: Managing Science in the Internet World. Baltimore: Johns Hopkins University Press, 2016. Pp. ix +206. ISBN 978-1-4214-1868-1. $\$ 34.95$ (hardback). doi:10.1017/S0007087417000796

Since the year 2000, all proposals for research funding from the US National Science Foundation (NSF) have been managed through a platform called FastLane. Developed in the 1990s, FastLane consolidated the traditional paper processes of grant application, approval and financial disbursement into a single computer system. This book examines its design and implementation and situates FastLane within the longer institutional history of the NSF and early Internet-era computing. 